\title{
3 次元海洋構造物に作用する非線形波力の計算法について
}

増田光一*. 永井孝志**. 柴山泰亮***

\section{1. 緒言}

著者らは前年の海講に执いて，基本的な形状である鉛 直円柱に作用する非線形波力の実用的な数值計算法を示 しその有用性を確認した（増田ら，1990）。しかし，そ こで対象とする海洋構造物を柱状体と限定することによ り，数值計算上多くの利点を有することになったが，反 面, 任意な 3 次元浮体に作用する非線形波力を算定する ことは出来ず，今後の課題であった．さらに，本報で取 り扱らコーン型 (内錐型) コンクリートプラットフォー ムは, 氷海域での使用を前提として開発された海洋構造 物であり舷側が自由表面と直交して扣らず，波が物体表 面上を遡上するような状況となる，このため，その物体 表面近傍での自由表面の非線形性は非常に大きく，この 舷側傾斜影響が波力の非線形性に及ぼす影響をも考慮し なければならないと考えられる.

以上のことから，本研究では 3 次元浮体に作用する非 線形波力の数值計算法を示すとともに，鉛直円柱及び円 筒型浮体について計算結果と実験結果を比較検討し, 本 計算手法の妥当性を明らかにすることを目的とする.さ らに舷側傾斜を有する海洋構造物に作用する非線形波力 の数值計算法を示し，コーン型浮体について計算結果と 実験結果とを比較検討し，2次の漂流力及び波力におよ ぼす舷側傾斜影響を明らかにすることも目的とする.

\section{2. 座 標 系}

流体は非粘性，非圧縮性の完全流体であり流体の運動 は非回転で速度ポテンシャル $\Phi$ の存在が保証される.

座標系は Fig. 1 に示すように静水面上に原点 $o$ を持つ 右手座標系である. 図中の $\Omega$ は流体領域, $S_{H}$ は物体 表面, $S_{B}$ は水底, $S_{F}$ は自由表面, $S_{R}$ は仮想境界, $S_{\infty}$ は無限遠方での境界を示し， $C_{H}, C_{R}$ はそれぞれ物体表 面，仮想境界と自由表面との交線である。笠た，仮想境 界を含む外部領域 $\Omega_{R}$ では, 便宜上 $\operatorname{or} \theta z$ の 円筒座標

\footnotetext{
* 正会員 工博 日本大学理工学部海洋建築工学科

** 正会員 工修 (株)大林組技術研究所

*** 工修 ニッサン・モータースポーッ・インターナショナル
} (株)
系を用いることにする。

な拈，1 次， 2 次の散乱波ポテンシャル $\phi_{d}^{(1)}, \phi_{d}{ }^{(2)}$ に関する境界值問題及び波力の定式化については前報と 同様なため割愛する.

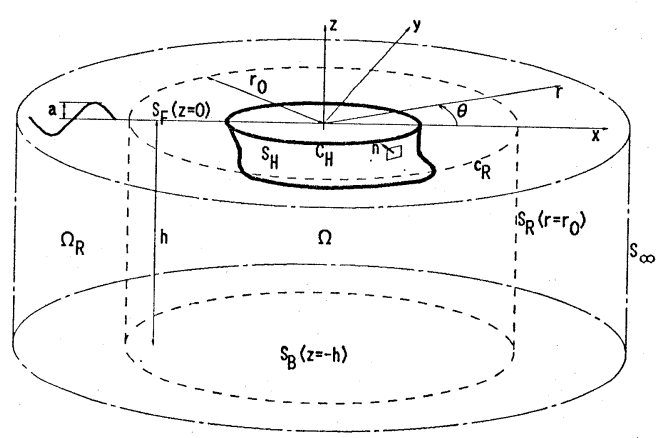

Figure 1: Coordinate system.

\section{3. 舷側傾斜影響}

ここでは, 経塚 (1982) が 2 次元物体を対象に示した 方法を基に，舷側が自由表面と直交しない構造物に作用 する浸水面積変化による波力（Run-up 波力）の計算法 を示す. 舷側が自由表面とケの角度で交わる場合, Fig. 2 に示すようであると考えられる. このとき，図中 $\Delta x$, $\Delta z$ を以下のように仮定すると，



Figure 2: Variation of wetted surface.

$$
\left.\begin{array}{l}
\Delta x=\eta^{(1)} \cot \gamma \\
\Delta z=\eta^{(1)}
\end{array}\right\}
$$

浸水面積変化による水平力 $F_{R x}$ 及び垂直力 $F_{R z}$ は,

$$
F_{R x}=-\rho \int_{C_{H}} \int_{\Delta z}\left(\Phi_{t}^{(1)}+g z\right) n_{x} d z d c
$$




$$
F_{R z}=-\rho \int_{C_{H}} \int_{\Delta x}\left(\Phi_{l}^{(1)}+g x \tan \gamma\right) d x d c
$$

で与えられる. よって, 最終的に 2 次の漂流力 $f_{0 j}{ }^{(2)}$ 及 び変動波力 $f_{j}^{(2)}$ は以下のようになる.

$$
\begin{aligned}
f_{0 j}^{(2)}= & -\frac{\rho}{4} \iint_{S_{H}} \nabla \phi^{(1)} \cdot \nabla \phi^{(1)^{*}} \mu_{j} d s \\
& +\frac{\rho \omega^{2}}{4 g} \int_{C_{H}} \phi^{(1)} \cdot \phi^{(1)^{*}} \mu_{j}{ }^{R} d c \cdots \cdots \cdots \cdots( \\
f_{j}^{(2)}= & 2 i \omega \rho \iint_{S_{F}} q \psi_{j} d s+2 i \omega \rho \iint_{S_{H}} \phi_{I}^{(2)} \mu_{j} d s \\
& -2 i \omega \rho \iint_{S_{H}} \phi_{j} \psi_{I n}^{(2)} d s \\
& -\frac{\rho}{4} \iint_{S_{H}} \nabla \phi^{(1)} \cdot \nabla \phi^{(1)} \mu_{j} d s \\
& -\frac{\rho \omega^{2}}{4 g} \int_{C_{H}} \phi^{(1) 2} \mu_{j}^{R} d c \cdots \cdots \cdots \cdots \cdots \cdots
\end{aligned}
$$

ここで,

$$
\left.\begin{array}{l}
\mu_{1}=n_{x} \\
\mu_{3}=n_{z} \\
\mu_{5}=\left(z-z_{G}\right) n_{x}-\left(x-x_{G}\right) n_{z} \\
\mu_{1}^{R}=n_{x} \\
\mu_{3}^{R}=\cot \gamma \\
\mu_{5}^{R}=-z_{G} n_{x}-\left(x-x_{G}\right) \cot \gamma
\end{array}\right\}
$$

で, $n_{x}, n_{y}, n_{z}$ は $S_{H}$ 上単位法線 $n$ の $x, y, z$ 方向 余弦を, $\left(x_{G}, y_{G}, z_{G}\right)$ は棈造物の 回転の中心である.

(4),（5）式より, 舷側傾斜影響は水平力には影響せ ず，垂直力及びモーメントの定常力と倍周波数成分に表 われることになる.

\section{4. 自由表面積分}

自由表面積分法に於いては（5）式第 1 項の評価が非 常に重要である. 本報では 3 次元波動場の解法にハイブ リッド境界要素法（永井ら，1990）を使用して外部の速 度ポテンシャル色固有関数列に表示している. そこで, 自由表面を離散化領域, 外部領域, 無限領域に分け以下 のように示す.

$$
\begin{aligned}
\iint_{S_{F}} q \psi_{j} d s= & \iint_{S_{F^{\prime} m}} q \psi_{j} d s+\int_{r_{0}}^{r_{1}} \int_{0}^{2 \pi} q \psi_{j} r d \theta d r \\
& +\int_{r_{1}}^{\infty} \int_{0}^{2 \pi} q \psi_{j} r d \theta d r \quad \ldots \ldots \cdots \cdots(8)
\end{aligned}
$$

ここで， $S_{F m}$ は自由表面離散化領域， $r_{0} ， r_{1}$ はそれぞ れ仮想境界及び無限領域までの距離であり, 以後に示す ように三角関数の直交性を利用するなどそれぞれの領域 で最適な手法を採用する。

\section{1 外部 領 域}

外部領域に拈ける自由表面積分では，円周方向につい て三角関数の直交性を利用して積分を行うのが有効であ る. 今, $x$ 軸に対して流場が対象であるとすると, 速度ポ テンシャル $\phi_{I}^{(1)}, \phi_{d}^{(1)}, \phi_{j}$ は以下のように表示される.

$$
\begin{aligned}
& \phi_{I}^{(1)}=\sum_{n=0}^{N} I_{n} \cos n \theta \\
& \phi_{d}^{(1)}=\sum_{n=0}^{N} S_{n} \cos n \theta \\
& \phi_{j}=\sum_{n=0}^{N} P_{j n} \cos n \theta
\end{aligned}
$$

ここで,

$$
\begin{aligned}
& I_{n}=-i \frac{a g}{\omega} Z_{0}(k, z) R_{n}^{I}(k r) \\
& S_{n}=-i \frac{a g}{\omega} \sum_{m=0}^{M} S_{m n} Z_{m}\left(k_{m}, z\right) R_{m n}\left(k_{m} r\right) \\
& P_{j n}=\sum_{m=0}^{M} P_{j m n} Z_{m}\left(k_{2 m}, z\right) R_{m n}\left(k_{2 m} r\right) \\
& Z_{m}\left(k_{m}, z\right)= \begin{cases}\frac{\cosh k(h+z)}{\cosh k h} ; & m=0 \\
\frac{\cos k_{m}(h+z)}{\cos k_{m} h} ; & m \geq 0\end{cases} \\
& R_{m n}\left(k_{m} r\right)= \begin{cases}\frac{H_{n}^{(1)}(k r)}{H_{n}^{(1)}\left(k r_{0}\right)} ; & m=0 \\
\frac{K_{n}\left(k_{m} r\right)}{K_{n}\left(k_{m} r_{0}\right)} ; & m \geq 0\end{cases} \\
& R_{n}^{I}=\varepsilon_{n} i^{n} J_{n}(k r)
\end{aligned}
$$

であり， $\varepsilon_{0}=1, \varepsilon_{n \geq 1}=2$ で, $H_{n}^{(1)}, K_{n}, J_{n}$ はそれぞれ $n$ 次の第 1 種ハンケル関数, 第 2 種変形ベッセル関数,

第 1 種ベッセル関数である. また， $k_{m}, k_{2 m}$ は

$$
\begin{aligned}
& -\frac{\omega^{2}}{g}=k_{m} \tan k_{m} h \ldots \\
& -\frac{4 \omega^{2}}{g}=k_{2 m} \tan k_{2 m} h
\end{aligned}
$$

の固有值である.

（8）式第 2 項は, 動径方向の積分にガウスの 4 点積 分を用いて $r_{0}$ から $r_{1}$ までをL個の幅Hの微小区間に 分割すれば,

$$
\begin{aligned}
& \int_{r_{0}}^{r_{1}} \int_{0}^{2 \pi} q \phi_{j} r d \theta d r \\
& =-\frac{2 \omega^{2} \rho}{g} \sum_{l=1}^{L} \sum_{i=1}^{4}\left[\Theta_{C}\left(P_{j}, S_{r}, S_{r}\right)+2 \Theta_{C}\left(P_{j}, I_{r}, S_{r}\right)\right. \\
& +\frac{1}{r^{2}}\left\{\Theta_{S}\left(P_{j}, S, S\right)+2 \Theta_{S}\left(P_{j}, I, S\right)\right\} \\
& +\frac{3}{2} \frac{\omega^{4}}{g^{2}}\left\{\Theta_{C}\left(P_{j}, S, S\right)+2 \Theta_{C}\left(P_{j}, I, S\right)\right\} \\
& -\frac{1}{2}\left\{\Theta_{C}\left(P_{j}, S, S_{z z}\right)+\Theta_{C}\left(P_{j}, I, S_{z z}\right)\right. \\
& \left.+\Theta_{C}\left(P_{j}, S, I_{z z}\right)\right] \bar{\xi} \bar{w}
\end{aligned}
$$

となる.ここで

$$
\begin{aligned}
& \Theta_{C}(A, B, C) \\
& \quad=\pi \sum_{m=0}^{N} \sum_{n=0}^{N} A_{m} B_{n}\left(\varepsilon_{m+n} C_{m+n}+\varepsilon_{i m-n \mid} C_{|m-n|}\right)
\end{aligned}
$$




$$
\begin{aligned}
\Theta_{S}(A, B, C) \\
=\pi\left[\sum_{m=1}^{N} m^{2} A_{0} B_{m} C_{m}+\sum_{n=1}^{N}\left(-\frac{1}{2}\right) A_{m} B_{n} n\right. \\
\quad \cdot\left\{\operatorname{sign}(m-n)|m-n| C_{|m-n|}\right. \\
\left.\left.\quad-(m+n) C_{m+n}\right\}\right] \ldots \ldots \ldots \ldots \ldots \ldots \cdots \cdots
\end{aligned}
$$

であり, $\varepsilon_{0}=1, \varepsilon_{n \geq 1}=1 / 2$ また $\bar{\xi}, \bar{w}$ は,

$$
\begin{aligned}
& \bar{\xi}=\frac{H}{2} \xi_{i}+\frac{2\left(n H+r_{0}\right)-H}{2} \\
& \bar{w}=\frac{H}{2} w_{i} \ldots \ldots \ldots \ldots \ldots \ldots \ldots \ldots \ldots \ldots
\end{aligned}
$$

で, $w_{i}$ はガウスの積分点 $\xi_{i}$ での重みである.

\section{2 無限 領 域}

無限領域では, 速度ポテンシャル $\phi_{I}^{(1)}, \phi_{d}^{(1)}, \phi_{j}$ を 漸近展開し, 以下のように表示する.

$$
\begin{aligned}
& \phi_{I^{(1)}} \simeq \sum_{n=0}^{N} \tilde{I}_{n} \sqrt{\frac{2}{\pi k r}} \cos \left(k r-\alpha_{n}\right) \cos n \theta \\
& (k r \gg 1) \cdots \cdots \cdots \cdots(25) \\
& \phi_{d}^{(1)} \simeq \sum_{n=0}^{N} \tilde{S}_{n} \sqrt{\frac{2}{\pi k r}} e^{i\left(k r-\alpha_{n}\right)} \cos n \theta \quad(k r \gg 1) \\
& \cdots \cdots \cdots \cdots \cdots \cdots \cdots \cdots \cdots \cdots \cdots \cdots \cdots \cdots \cdots \cdots \cdots
\end{aligned}
$$

ここで

$$
\begin{aligned}
& \alpha_{n}=\frac{1}{4}(2 n+1) \pi \\
& \tilde{I}_{n}=-i \frac{a g}{\omega} \varepsilon_{n} i^{n} \ldots \ldots \ldots \ldots . . . . . . \\
& \tilde{S}_{n}=-i \frac{a g}{\omega} \frac{S_{0 n}}{H_{n}^{(1)}\left(k r_{0}\right)} \\
& \tilde{P}_{j n}=\frac{P_{j 0 n}}{H_{n}^{(1)}\left(k_{2} r_{0}\right)} \ldots \ldots .
\end{aligned}
$$

である.（8）式第 3 項の動径方向の無限積分に EatockTaylor ら (1987) が示したように Fresnel の関数を応用 すると,

$$
\begin{aligned}
\int_{r_{1}}^{\infty} \int_{0}^{2 \pi} q \phi_{j} r d \theta d r \\
=-\frac{2 \omega^{2} \rho}{g}\left[\sqrt{\frac{2}{\pi k_{2}}} \frac{k}{\pi}\right. \\
\\
\quad \cdot\left\{-3 \operatorname{sech}^{2} k h \Theta^{+}\left(\tilde{P}_{j}, \tilde{I}, \tilde{S}\right) F\left(2 k+k_{2}, r_{1}\right)\right. \\
\quad+\left(3 \tanh ^{2} k h+1\right) \Theta^{-}\left(\tilde{P}_{j}, \tilde{I}, \tilde{S}\right) F\left(k_{2}, r_{1}\right) \\
\left.\left.\quad-3 \operatorname{sech}^{2} k h \Theta^{+}\left(\tilde{P}_{j}, \tilde{S}, \tilde{S}\right) F\left(2 k+k_{2}, r_{1}\right)\right\}\right]
\end{aligned}
$$

のように示される.ここで,

$$
\begin{aligned}
\Theta^{ \pm} & (A, B, C) \\
= & \sum_{m=0}^{N} \sum_{n=0}^{N} A_{m} B_{n}\left\{\varepsilon_{m+n} C_{m+n} e^{-i\left(\alpha_{m} \pm \alpha_{n}+\alpha m+n\right)}\right. \\
& \left.+\varepsilon_{|m-n|} C_{|m-n|} e^{-i\left(\alpha_{m} \pm \alpha_{n}+\alpha|m-n|\right)}\right\}
\end{aligned}
$$

$$
\begin{aligned}
F\left(\beta, r_{1}\right)= & \sqrt{\frac{2 \pi}{\beta}}\left[\left\{\frac{1}{2}-C\left(\sqrt{\frac{2 \beta r_{1}}{\pi}}\right)\right\}\right. \\
& \left.-i\left\{\frac{1}{2}-S\left(\sqrt{\frac{2 \beta r_{1}}{\pi}}\right)\right\}\right] .
\end{aligned}
$$

であり， $S, C$ は Fresnel の正弦及び余弦関数である.

\section{3 離散化領域}

（8）式第 1 項の離散化領域内での自由表面積分は以 下のように示される.

$$
\begin{aligned}
\iint_{S_{F m}} q \phi_{j} d s= & -\frac{2 \omega^{2} \rho}{g} \iint_{S_{F m}} \phi_{i}\left\{\phi_{d x}^{(1) 2}\right. \\
& +2 \phi_{I x}^{(1)} \phi_{d x}^{(1)}+\phi_{d y}^{(1) 2}+2 \phi_{I y}^{(1)} \phi_{d y}^{(1)} \\
& +\frac{3}{2} \frac{\omega^{4}}{g^{2}}\left(\phi_{d}^{(1) 2}+2 \phi_{I}^{(1)} \phi_{d}^{(1)}\right) \\
& \left.-\frac{1}{2}\left(\phi^{(1)} \phi_{d z z}^{(1)}+k^{2} \dot{\phi}_{I}^{(1)} \phi_{d}^{(1)}\right)\right\} d s
\end{aligned}
$$

\section{5. 水槽実験}

実験に使用した模型は Fig. 3〜4 に示す円筒型浮体 及びューン型浮体であり, 三分力計を介して吃水 $d$ が $0.1 \mathrm{~m}$ になるよらに固定した. 水深 $h$ は $1.0 \mathrm{~m}$ とし, 周期 $0.8 \sim 2.1 \mathrm{sec}$ の範囲の規則波を波振幅 $a=0.01 \sim$ $0.03 \mathrm{~m}$ の間で変化させ造波し, $F_{x}, F_{z}, M_{y}$ を計測し た. 計測されたデータは, 定常な 5 波をサンプリング数 2048点で $\mathrm{AD}$ 変換した後, 高速フーリェ変換により各 周波数成分に分離した. また，漂流力については造波を 開始する直前の計測値を基準とし，それと定常な 5 波の 平均值との差を波漂力 $f_{0}^{(2)}$ とした.

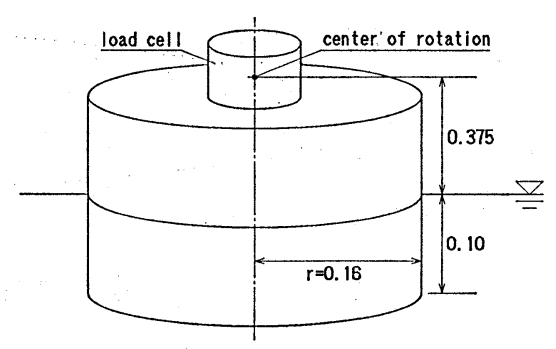

Figure 3: Model configuration of circular dock.

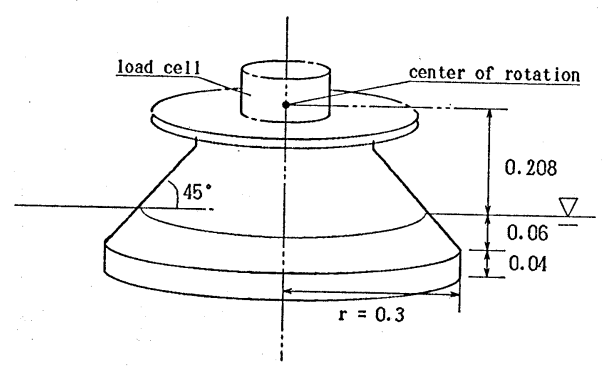

Figure 4: Model configuration of cone shaped structure. 


\section{6. 結果及び考察}

\section{1 計算精度の検討}

鉛直円柱を例にとり本報で示した手法と実験結果及び Eatock-Taylor（1987）の解析解とを比較する. Fig. 5 飞水深半径比 $h / r=5$ の鉛直円柱に作用する 2 次水平波 力 $f_{x}^{(2)}$ を示す. 解析解と本計算結果はよく一致してお り, 本数值計算手法の妥当性を確認する事が出来る.

\section{2 円筒型浮体}

Fig. 6 8 に円筒型浮体に作用する 2 次の漂流力を, Fig. 9 11 に2 次の変動波力を示す. 実験 結 果にばら つきが見られるものの, 計算結果と実験結果は良い相関 を示して扮り 3 次元浮体に扮いて子本手法の妥当性が確 認できる.

6.3 コーン型浮体

Fig. 12 14 ヒコーン型浮体に作用する 2 次の漂流力

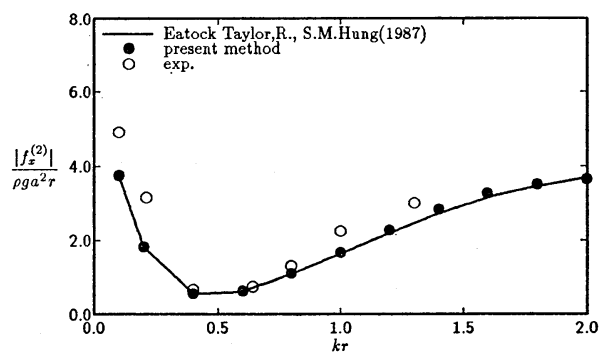

Figure 5: Second-order horizontal wave forces on a circular cylinder.

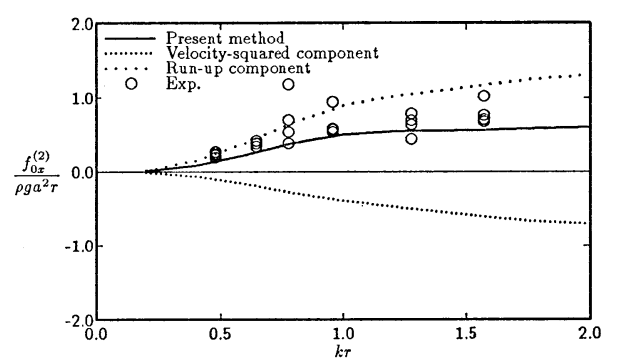

Figure 6: Second-order horizontal wave drift forces on a circular dock.

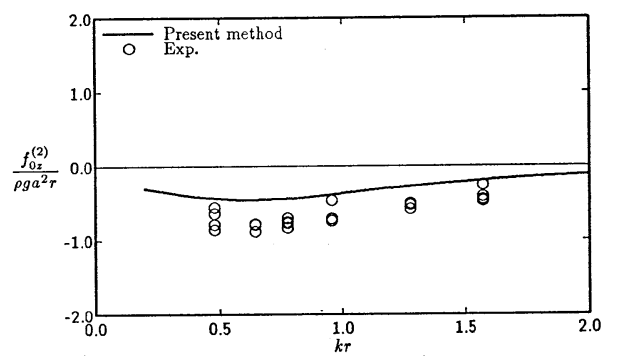

Figure 7: Second-order vertical wave drift forces on a circular dock.



Figure 8: Second-order wave drift moments on a circular dock.

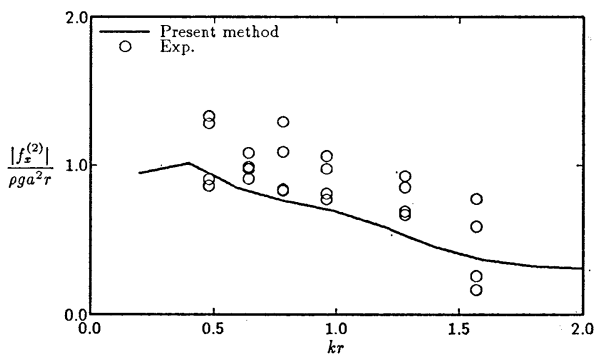

Figure 9: Second-order horizontal wave forces on a circular dock.

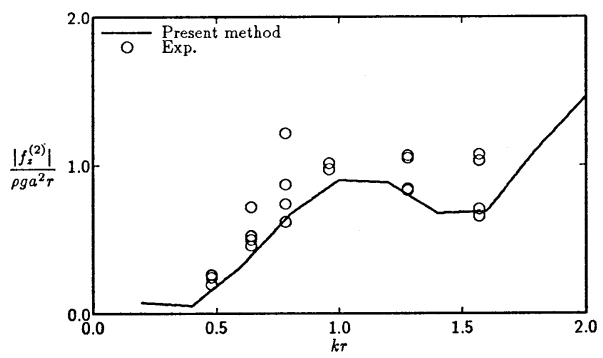

Figure10: Second-order vertical wave forces on a circular dock.

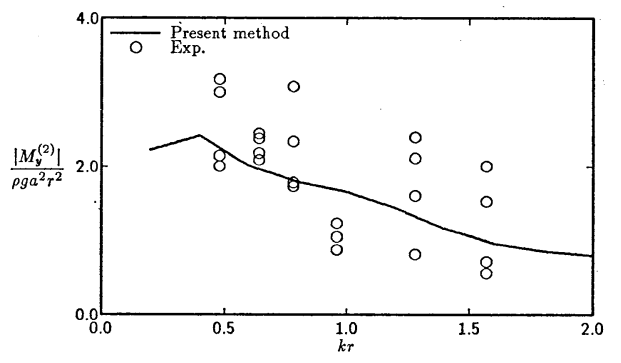

Figure11: Second-order wave moments on a circular dock.

を示す. 水平波漂流力 $f_{0 x}(2)$ 飞は船側傾斜の 影響は表 れないため, 計算值と実験值は良く一致している. 舷側 傾斜影響がある鉛直漂流力 $f_{0 z}{ }^{(2)}$ 及び漂流モーメント $M_{0 y}{ }^{(2)}$ についても，計算値と実験値は良い相関を示し ていると思われる. 特に鉛直漂流力については，舷側傾 


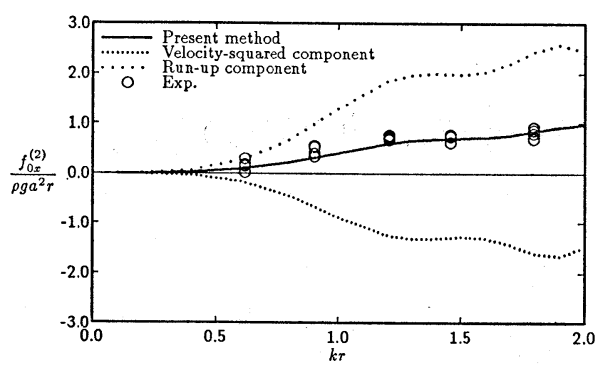

Figure12: Second-order horizontal wave drift forces on a cone shaped structure.



Figure13: Second-order vertical wave drift forces on a cone shaped structure.

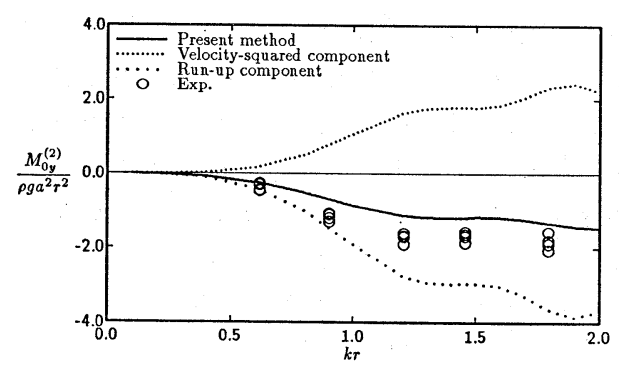

Figure14: Second-order horizontal wave forces on a cone shaped structure.

斜を考慮しない従来の方法では圧力方程式の速度 2 乗項 に由来する項のみで評価することになるため，現象をま ったく説明できないことがわかった。

次に, Fig. 15 17 に2 次の波力を示す. 計算値と実 験值の相関は良く，本報で示した航側傾斜影響の評価方 法の妥当性が明らかになった.

\section{7. 結言}

本研究で得られた結論は以下のと叔りである.

1. 鉛直円柱に作用する 2 次の波力について，計算結 果と解析解及び実験結果とを比較し, 本研究で示した計 算手法の妥当性が確認された.

2. 円筒型浮体に作用する 2 次の波力についても, 計 算結果と実験結果とは良い相関を示した.

3. コーン型浮体に作用する 2 次の漂流力及び波力に ついて計算結果と実験結果を比較検討した結果，両者は

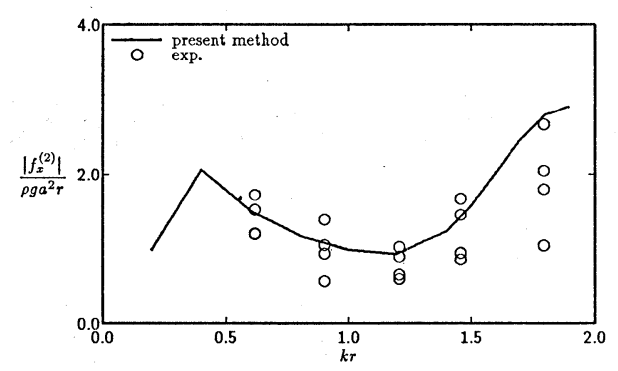

Figure15: Second-order horizontal wave forces on a cone shaped structure.



Figure16: Second-order vertical wave forces on a cone shaped structure.

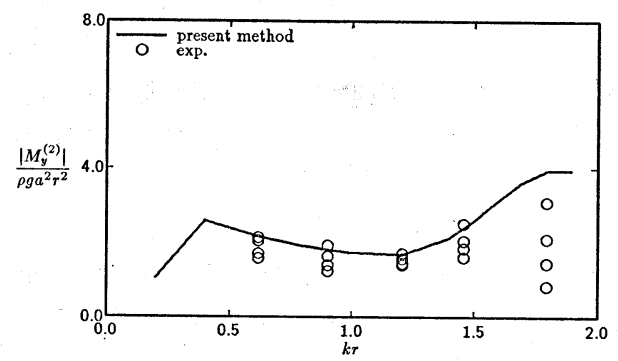

Figure17: Second-order wave moments on a cone shaped structure.

良い相関を示し，特に鉛 直力及びモーメントについて は，舷側傾斜の影響を考慮しなければ現象を説明できな いことが明らかになった。

\section{参考文 献}

経塚雄策 (1982)： 2 次元物体に働く非線形流体力について（第 3 報舫側傾斜影響), 日本造船学会論文集, 第 150 号, pp. 166-174.

酒向裕司 - 松井徹哉・鈴木達人 ·佐野公俊 (1989)：3 次元物 体に加わる 2 次波強制力の計算法について, 日本建築学会 大会学術講演梗概集, pp. 1121-1122.

永井孝志 ・増田光一 (1990)：浅海域における円柱浮体に働く 2 次長周期波力に関する研究, 関西造船協会誌, 第 213 号, pp. 109-114.

増田光一・永井孝志 (1990)：2 本の柱状体に作用する非線形 波力に関する研究, 第 37 回海岸工学講演会論文集, pp. 659-663.

Eatock Taylor, R. and S. M. Hung (1987): Second order diffraction forces on a vertical cylinder in regular waves, Applied Ocean Research, Vol. 9, No. 1, pp. 19-30. 